\title{
Los mitos y su función en la cultura
}

\author{
Myths and their role in culture
}

\author{
Germán Martin Dartsch Dreidemie \\ Consejo Nacional de Investigaciones Científicas y Técnicas, Argentina \\ gdartsch@mendoza-conicet.gob.ar
}

Fecha de recepción: 21/01/2015. Reenvios: 3/12/2015 - 5/02/2016.

Fecha de aceptación: 20/5/2016. Fecha de publicación: 13/06/2016.

\begin{abstract}
Resumen: En casi todas las religiones, los dioses, seres primigenios y creadores de la naturaleza, son los responsables de que exista la cultura humana. A veces los mitos explican el surgimiento de la cultura como forma de trascender lo natural, en este caso son las acciones prodigiosas de los dioses las que la hacen surgir. Pero muchas veces la discontinuidad entre naturaleza y cultura es fruto de un pecado o la ruptura de una prohibición por parte de dioses o de la humanidad, como en la expulsión del ser humano del paraíso en la Biblia, o del origen del nacimiento y la muerte en el mito fundacional de Japón. Así, y siguiendo el pensamiento de Lévi-Strauss, la cultura viene a cubrir una falta en la naturaleza y a asumir el orden humano por sobre lo que la naturaleza deja al azar, y es nuestra hipótesis que la función de los mitos es explicar esa falta, así como ejecutar una operación lógica que recupere ese tiempo perdido que, según Lévi-Strauss, no existe en un sentido histórico: el origen de la humanidad. También vamos a esbozar (apoyándonos en la obra de Jacques Lacan) la idea de que existe además una función psicológica de los mitos, al explicar la castración en el Otro y preservar, en la misma operación, la estructura como una totalidad completa.
\end{abstract}

Palabras clave: Mitología, cultura, tiempo mítico, antropología, psicoanálisis.

\begin{abstract}
In almost all religions, gods, primeval beings and creators of nature, are responsible for the existence of human culture. In some occasions myths explain the emergence of culture as a way to transcend the natural world. In that case, it is the prodigious actions of the gods that create human culture. However, discontinuity between nature and culture often results from a sin or the violation of a ban by gods or by humans, such as man's banishment from paradise in the Bible or the origin of birth and death in the founding myth of Japan. Consequently, based on Lévi-Strauss, culture fills a void in nature and assumes the human order, taking what nature has left to chance. It is our hypothesis that the function of myth is to explain this void as well as to perform a logical operation that recovers the lost time that, according to LéviStrauss, does not exist in an historical-chronological sense: the origin of humankind. In addition, we will outline (following the ideas of Jacques Lacan) the hypothesis that myths also have a psychological function, by explaining castration in the Other and preserving the structure in the same operation as a complete whole.
\end{abstract}

Keywords: Mythology; Culture; Mythical Time; Anthropology; Psychoanalysis

Germán Dartsch 


\section{Introducción}

En casi todas las religiones, los dioses, seres primigenios y creadores de la naturaleza, son los responsables de que exista la cultura humana. Los dioses participan, por lo tanto, a su vez de lo natural y de lo cultural. En este contexto, los dioses toman a su cargo el dar cuenta de la diferenciación entre naturaleza y cultura, y los mitos relatan el porqué de esta ruptura.

A veces los mitos explican el surgimiento de la cultura como forma de trascender lo natural, en este caso son las acciones prodigiosas de los dioses las que la hacen surgir. Pero muchas veces la discontinuidad entre naturaleza y cultura es fruto de un pecado o de la ruptura de una prohibición por parte de los dioses o de la humanidad, como en el caso de la expulsión del ser humano del paraíso en la Biblia, o del origen del nacimiento y la muerte en el mito fundacional de Japón. Lo que es invariante es que existe un momento fuera del tiempo cronológico (en un tiempo mítico) que da cuenta de, habla de una falta, una imperfección o un suceso más o menos ominoso que hace necesario que la cultura se monte sobre lo natural y que el orden cultural ponga reglas allí donde la naturaleza deja las cosas libradas al azar (esto es patente en las normas que rigen los sistemas de parentesco, las jerarquías sociales, los rituales mortuorios, etc.).

Así, repetimos siguiendo el pensamiento de Lévi-Strauss, la cultura viene a cubrir una falta en la naturaleza y a asumir el orden humano por sobre lo que la naturaleza deja al azar. Pero para decir más, es nuestra hipótesis que la función de los mitos es hablar de esa falta así como ejecutar una operación lógica que recupere ese tiempo perdido que, según Lévi-Strauss, no existe en un sentido histórico: el origen de la humanidad. Para ello vamos a apoyarnos fundamentalmente en la obra de Jacques Lacan para trabajar nuestra idea central: la función principal de los mitos es explicar esta falta (castración) en el Otro (en tanto que este Otro es sostén de lo simbólico) y preservar en la misma operación la estructura como una totalidad completa, aunque completa solo a nivel imaginario. Asimismo, vamos a trabajar la cultura como esta estructura simbólica que, en su carácter de garante del "sentido del ser del sujeto", debe ser salvaguardada de la falta, de ese vacío que no es sino la no existencia de un sentido del ser del sujeto.

\section{Naturaleza y cultura}

La relación entre naturaleza y cultura ha sido tan problemática para el pensamiento que a ha llevado a la filosofía y a la teoría a preguntarse sobre la esencia del ser humano. Podemos citar a contractualistas (Hobbes, Locke, Rousseau, incluso Kant) para quienes era de suma importancia descubrir cómo habría sido el ser humano en un hipotético estado de naturaleza para así poder dar legitimidad a sus filosofías. Pero también podemos citar a otros pensadores como Heidegger, para quien la técnica es la esencia del ser humano, sentencia con la cual queda descartada toda posibilidad de un estado de naturaleza anterior a la cultura a favor de la idea de que fuera de la cultura no existiría humanidad. 
Pero podemos ir aún más atrás, a las religiones y las mitologías, las cuales encontraban en los dioses y seres míticos la explicación entre la ruptura o continuidad que pudiera existir entre naturaleza y cultura. Así, en casi todas las religiones politeístas, los dioses, seres primigenios y creadores de la naturaleza, son responsables de que exista la cultura humana. A veces los mitos explican el surgimiento de la cultura como forma de trascender lo natural, en este caso son las acciones prodigiosas de los dioses las que la hacen surgir. Pero muchas veces, y es este el caso del mito que tomaremos como ejemplo en este ensayo, la discontinuidad entre naturaleza y cultura es fruto de un pecado o la ruptura de una prohibición por parte de dioses o la humanidad, como en la expulsión del ser humano del paraíso en la Biblia, o del origen del nacimiento y la muerte en el mito fundacional de Japón.

Así, y siguiendo el pensamiento de Lévi-Strauss, la cultura viene a cubrir una falta en la naturaleza y a asumir el orden humano por sobre lo que la naturaleza deja al azar', y es nuestra hipótesis que la función de los mitos es hablar y velar esa falta así como ejecutar una operación lógica que recupere ese tiempo perdido que, según Lévi-Strauss, no existe en un sentido histórico: el origen de la humanidad. Además, vamos a esbozar la idea de que existe una función psicológica de los mitos, al explicar la castración en el $\mathrm{Otro}^{2}$ y preservar, en el nivel imaginario, en la misma operación, la estructura como una totalidad completa. Es decir, el mito (entre los cuales podríamos, en un estudio más extenso, agrupar religiones, ideologías políticas, culturas, nacionalismos y todo tipo de relatos que funcionan como elementos cohesionantes de un determinado segmento social) vela la castración de quienes ocupan la posición del Otro para el sujeto para preservar así el tesoro de los significantes que es el Otro de la estructura. Más adelante explicaremos cada uno de estos puntos.

\section{La no continuidad entre naturaleza y cultura}

Siguiendo el pensamiento del antropólogo Claude Lévi-Strauss, si bien existe una no continuidad entre naturaleza y cultura, esta no es tan simple como el reemplazo de una por otra, ni tampoco sería correcto suponer que una existe en ausencia de la otra, sino que ambas coexisten a través de complejas relaciones que conviene analizar con minucia y precaución, pues en la mayoría de los

1 De esto hablaremos más en detalle en el próximo apartado.

2 En psicoanálisis lacaniano, Otro, con O mayúscula, se diferencia del otro (con o minúscula) en tanto que este otro es un semejante con el cual el sujeto puede operar identificaciones. El Otro, en cambio, es la alteridad radical imposible de identificación, metaforización o simbolización. Es a sí mismo el tesoro de los significantes, es decir, sostén del registro simbólico. El Otro es el otro completa e irreductiblemente otro, aunque existen referentes que vienen a ocupar el lugar de este Otro para el sujeto (y ser sostenes de la función simbólica) tales como la figura omnipotente de los padres en la infancia, y luego, progresivamente y según edad y posición sociocultural, dioses, grandes figuras políticas, ideologías y sus referentes, el Estado, las leyes. Sin embargo, como se explica en este trabajo, el Otro está atravesado por una falta que hace ilusión a que ese Otro es incompleto, y esa incompletitud (castración en lenguaje técnico) radica en que no existe respuesta del Otro que justifique el ser del sujeto, lo cual es fuente de angustia. De aquí que la racionalidad mítica tenga como función suturar esta falta y la angustia psíquica que la misma conlleva. El mito es, por tanto, una cosmovisión totalizante en la que todo (incluido el sujeto) tiene una razón de ser y un lugar, siendo el Otro garante de este orden. En los esquemas lacanianos, el Otro se simboliza con una A mayúscula pues en francés Otro se traduce como Autre. Esto es debido a que Lacan mismo quería mantener intactas las letras de sus matemas más allá de las traducciones. 
casos el comportamiento de los sujetos humanos tiene que ver con integraciones entre ambas. Al respecto, dice Lévi-Strauss que "en la mayoría de los casos... la respuesta del sujeto constituye una verdadera integración de las fuentes biológicas y sociales de su comportamiento" (Lévi-Strauss, 1974). El autor se pregunta, entonces, dónde termina la naturaleza y dónde comienza la cultura, pues admite que la oposición entre ambas es necesaria para comprender los fenómenos sociales. En el camino de su razonamiento, plantea Lévi-Strauss que:

la ausencia de reglas parece aportar el criterio más seguro para establecer la distinción entre un proceso natural y una cultura... todo lo que es universal en el hombre corresponde al orden de la naturaleza y se caracteriza por la espontaneidad, mientras que todo lo que está sujeto a una norma pertenece a la cultura y presenta los atributos de lo relativo y de lo particular. (1974, p. 41).

Sin embargo, si bien lo natural es universal y no está sujeto a normas; y lo cultural es particular y reglado, existe una norma que constituye una operación de pasaje entre lo natural y lo cultural, y que tiene la particularidad de ser una norma, pero a la vez ser universal a todas las sociedades. Se trata de la prohibición del incesto. Es a través del análisis del problema del incesto que Lévi-Strauss podrá empezar a esclarecer la relación existente entre naturaleza y cultura.

\section{La prohibición del incesto como La Intervención de la cultura sobre la naturaleza: filia- ción y alianza}

El origen de la prohibición del incesto no puede encontrarse en lo histórico. Lévi-Strauss, que busca explicar por qué se presenta en todas las sociedades, expone que:

No tiene origen natural ni cultural ni es un compuesto de ambos. Constituye el movimiento fundamental gracias al cual, pero sobre todo en el cual, se cumple el pasaje de la naturaleza a la cultura. Constituye el vínculo de unión entre una y otra. Opera, y por sí misma constituye el advenimiento de un nuevo orden. (1974, p. 59)

La prohibición del incesto permite, entonces, que Lévi-Strauss pueda encontrar en ella una operación de pasaje en el cual la cultura afirma su predominancia sobre lo natural y, asimismo, afirma la predominancia de lo colectivo sobre el individuo en un campo primordial para el grupo. Así, si las relaciones familiares están fuera del control humano en lo que respecta al orden de la filiación (relación padres-hijos), pues nada puede decidir el sujeto ni el grupo sobre los padres que le tocan a cada uno, ni decidir a priori el hijo que habrá de tocarle, la naturaleza sí deja un vacío con respecto a otro tipo de relación familiar: la alianza (relaciones esposo-esposa). La naturaleza pone al ser humano en la necesidad de establecer alianzas con miembros del sexo opuesto para procrear, pero no establece ninguna regularidad sobre cómo debe realizarse esto. Así, donde la naturaleza deja las cosas libradas al azar, la cultura impone su orden (Lévi-Strauss, 1974). 
La prohibición del incesto es lo que Lévi-Strauss llama La Intervención, con mayúsculas, pues se trata de una ley mayor y fundacional que constituye el advenimiento de un nuevo orden: la cultura.

\section{El advenimiento de un nuevo orden y la estructura social}

La Intervención, entonces, hace que se sustituya el azar por la organización. Así, una vez regladas las alianzas y constituidas las estructuras del parentesco en el grupo, lo sexual debe estar reglado, pues se trata de un campo primordial y estratégico para el grupo en el cual se encuentran insertos los individuos. Esto se debe a que la naturaleza deja al ser humano en riesgo a la hora de procurarle sustento y el producto del trabajo humano es escaso y de la necesidad de supervivencia del grupo adviene la necesidad de la división del trabajo. La importancia del matrimonio es, por tanto, económica y es por esto que las alianzas deben estar regladas. La prohibición del incesto permite al grupo evitar que existan privilegios sobre los cónyuges posibles por pertenecer a una familia determinada ${ }^{3}$. Así, mediante esta regla el grupo vigila un valor esencial y garantiza una relativa igualdad de condiciones entre sus miembros a la hora de establecer alianzas.

Ahora bien, toda prohibición es una prescripción y la regla cumple una función posibilitadora: a la vez que prohíbe, permite y asigna. Así, la prohibición del incesto es a la vez prescripción de la exogamia, es un sistema cuya nomenclatura permite determinar el círculo de parientes y personas allegadas y distingue dos categorías: cónyuges posibles y cónyuges prohibidos. La prohibición, entonces, erige una estructura de parentescos que se encuentra en la base de la estructura social: una vez que la cultura advino con sus reglas, las relaciones humanas necesariamente estarán regladas toda vez que el grupo deba velar por su predominancia sobre el individuo, pero a la vez, y dado que los individuos son formados en este sistema de reglas, que es un sistema simbólico, un sistema de signos, la estructura social será condición necesaria para la existencia del sujeto tanto como de la sociedad misma. El sujeto, quien en conjunto sostiene a la sociedad, surge del sistema del sentido social, el cual es preexistente. Lévi-Strauss asegura, entonces, que lo simbólico es a priori en el universo humano.

\section{La función social del mito}

Ahora bien, ya antes dijimos que el pasaje de la naturaleza a la cultura no puede encontrarse en lo histórico, sino que es una operación lógica. Pero el sistema del sentido social, como aseguran las teorías de la semiología y el análisis del discurso (Eliseo Verón, Charles Peirce, etc.), o también como dijera Lacan con respecto al lazo social, se sustenta, o mejor dicho existe, en los discursos sociales (para Lacan, como lo expresa en el seminario 19, los discursos hacen lazo social. Los distintos discursos son modos diferentes de organizar el lazo social (Lacan, 2012). ¿Qué discursos son los que

$3 \quad$ Lévi-Strauss se refiere a las mujeres exclusivamente. Al no estar en condiciones de contestar que sean las mujeres necesariamente el objeto de intercambio, pero tampoco estar de acuerdo con esto, preferimos no especificar si hablamos de mujeres u hombres. 
dotan de sentido y explican ese origen que está perdido, que es una falta? Nosotros exponemos que los mitos, sobre todo los mitos fundacionales que explican el origen del mundo, la humanidad y las naciones, son los relatos que sostienen, o al menos sostuvieron, la cohesión social.

Para Lévi-Strauss, el mito está, al igual que las entidades lingüísticas (el mito es, de hecho, una entidad lingüística), formado por unidades constitutivas como los fonemas, morfemas, semantemas, etc. Pero distingue, además, elementos constitutivos de un orden más complejo y que, según el autor, son unidades constitutivas mayores a las que denomima mitemas. Asimismo, Lévi-Strauss postula que estas unidades constitutivas del mito no son relaciones aisladas sino"haces de relaciones, y que sólo en forma de combinaciones de estos haces las unidades constitutivas adquieren una función significante. ... Este sistema es... un sistema de dos dimensiones, a la vez diacrónico y sincrónico" (Lévi-Strauss, 2011, pp. 233-234). Así, son las relaciones entre los mitemas, tomados tanto en la dimensión del devenir cronológico del relato como de su devenir lógico -es decir, de mitemas que están relacionados entre sí directamente, pero que en el relato aparecen separados por el tiempo- son los que permiten echar luz sobre la significación del mito.

\section{El mito y el origen humano}

Nuestra intención es adoptar el concepto de mito en sentido amplio, haciendo referencia a todo relato que recupera un tiempo no cronológico, sino lógico. Otro punto a tener en cuenta: los mitos se remontan a los orígenes para dotar de sentido el presente. En este sentido, se puede tomar como mito también la epopeya política de un dirigente del cual se es partidario o la epopeya, de características muy parecidas a los mitos heroicos, de un deportista o equipo deportivo del cual se es aficionado o aficionada. Esto es válido toda vez que estos relatos cumplen una función de dotar de sentido racional a una elección que el sujeto hace en función de motivos no racionales. El mismo Lévi-Strauss nos autoriza a pensar así, tal como expone en su escrito La estructura de los mitos al asegurar que "nada se asemeja más al pensamiento mítico que la ideología política" (Lévi-Strauss, 2011, p. 232). Así como uno no elige la cultura en la que nace, pero debe poder explicar por qué se siente parte de ella (aquí intervienen los mitos), un partido político o un equipo de fútbol muchas veces tampoco se elige sino que más bien se adopta en función del grupo de pertenencia del sujeto o se hereda por tradición familiar, pero si se le pregunta al sujeto la razón de su preferencia, seguramente acuda a relatos sobre las hazañas de su equipo antes que aceptar las razones antes mencionadas. Si vemos las cosas así, todo relato, independientemente de ser un mito o no en sentido estricto, puede funcionar como mito cuando su función cumple las características que exponemos.

Pero la eficacia del mito no sería tal si solo se remitiera al pasado para dotar de sentido el presente como si de una explicación histórica se tratara, sino que el mito participa a la vez del pasado, del presente y del futuro. Dice Lévi-Strauss que "el valor intrínseco atribuido al mito proviene de que estos acontecimientos, que se suponen ocurridos en un momento del tiempo, forman también 
una estructura permanente" (Lévi-Strauss, 2011, p. 232). Es decir que el mito cobra su mayor importancia, puesto que su eficacia, su capacidad de producir efectos en la sociedad y en el individuo, no se actualiza en función de alguna especie de genealogía histórica, sino que es el mito en sí mismo el que actúa en tiempo presente sobre los sujetos y el grupo. Al respecto, resulta ilustrativo un ejemplo tomado de la vida política: a 60 años de su muerte, un documental ruso que hablaba sobre la vida de Stalin, presidente del Consejo de Ministros de la URSS entre 1941 y 1953, aseguraba que "Stalin está siempre con nosotros y nos divide como si se fuera a presentar mañana a elecciones" (El País edición digital, 2013). Este ejemplo muestra claramente cómo el relato de los hechos ocurridos durante su régimen tiene efecto sobre el presente aún hoy, y que se sienten como independientes de su legado material. Algo parecido se puede decir del peronismo en Argentina. En estos casos, el relato de las hazañas políticas de un determinado político toma dimensiones míticas, puesto que constituye una estructura actual en torno a la cual se asignan lugares y se toman posiciones que han de mantenerse en la actualidad.

Vayamos a lo que nos interesa: si el mito cumple la importante función de sostener la estructura, entonces, el paso de la naturaleza a la cultura, que ya dijimos no tiene origen histórico sino que es una operación lógica, deberá también contar con un mito que explique este origen de la cultura y lo humano. Es el caso de los mitos fundacionales con los que cada cultura a lo largo de la historia ha buscado explicar -no tanto por ansias de conocimientos sino para sostener el orden establecido- el surgimiento del universo propiamente humano. En estos mitos suele haber explícitas referencias a relaciones problemáticas o rupturas con la naturaleza y violaciones de tabúes que explican cómo el ser humano abandona la naturaleza para ingresar en el mundo de la cultura. Ya citamos un ejemplo conocido por todos: la expulsión de Adán y Eva del Edén, la que se motiva por la ruptura de un tabú impuesto por Dios a los sujetos humanos primigenios.

En el mito de Izanami e Izanagi, mito fundacional del shintoísmo, religión típica de Japón, la necesidad de la muerte y los nacimientos se explica como resultado de un episodio vivido por estos dioses. Cuenta el mito que originalmente el mundo era una masa indiferenciada de agua, separada por un puente del mundo de los dioses. Los dioses, ajenos a esta argamasa y sin un claro plan para esta misma, encargaron a Izanagi e Izanami (hermano y hermana respectivamente), los más jóvenes de entre ellos, un yari (lanza tradicional japonesa) que debían utilizar para dar forma a ese caos. Ambos se dirigieron, entonces, al puente que pendía sobre el océano condensado de materia primigenia, y lo penetraron con esta yari (sin duda un significante fálico), y luego la levantaron. De la yari cayeron unas gotas que, en el camino de vuelta hacia el océano, se solidificaron dando así origen a las islas que componen el Japón. Al ver esto, los jóvenes dioses bajaron a las islas y allí se dieron a la tarea de explorar, a la vez que crear lo existente en este nuevo mundo. Luego de crear/descubrir la naturaleza, ambos realizaron la primera ceremonia matrimonial y ya casados tuvieron como hijos una gran cantidad de dioses menores. Sin embargo, uno de esos dioses fue Kagatushi, dios del fuego, compuesto de fuego él mismo, que en el proceso de su nacimiento dio muerte a Izanami incinerándola. Izanagi, furioso, dio muerte al recién nacido Kagatsushi y fue al yomi (mundo de los muertos) a buscar a su fallecida esposa. 
Una vez reunidos de nuevo en el yomi los esposos, Izanami daría a Izanagi la triste noticia de que no podía volver al mundo de los vivos, pues ya había comido y bebido los alimentos del yomi. Sin embargo, prometió hablar con los regentes del yomi para convencerlos de que la dejaran regresar. Solo una gran prohibición dio Izanami a su esposo: mientras ella llevara adelante la negociación, Izanagi debía permanecer afuera y bajo ningún aspecto mirar al interior del recinto donde ella entraría. Izanagi, no obstante, se impacientó tras una larga espera, y se asomó para encontrarse con la horripilante visión del cuerpo descompuesto de Izanami. Esto desató la ira de la diosa, puesto que el dios había violado la estricta prohibición que rige en el yomi de jamás mirar la verdadera forma de un ser fallecido, lo que trajo como resultado que Izanami, sobre quien cayó el castigo a pesar de no haber sido la culpable, debiera matar a mil personas por día como compensación. De esta manera, Izanami pasó a ser no solo la diosa de la creación, sino también la diosa de la muerte. Frente a esto, Izanagi rompió su lazo marital y respondió a su exesposa tomando como misión el dar nacimiento a mil quinientas diariamente, convirtiéndose en dios de la vida y en el mismo acto engendrando, por sí mismo, a Amaterasu (la diosa sol), Tsukuyomi (el dios luna) y Susanoo (el dios del viento, las mareas, las tormentas y las tempestades). Más tarde, y en otra línea de tiempo pero que puede relacionarse sincrónicamente con lo ya dicho gracias al método de Lévi-Strauss, será uno de los nietos de Izanagi quien, otra vez por violar una prohibición, deberá afrontar que tanto él como su descendencia tengan un período de vida limitado, lo que da origen a la humanidad.

En resumen, podemos decir que el mito cumple la función de ocupar un espacio intermedio entre polos opuestos, tal como Lévi-Strauss lo dice de los dioses al interior de los mitos. A partir del mito se vela, justifica, sostiene, legitima y proyecta hacia el futuro una determinada estructura social. Por tanto, los mitos conjugan pasado, presente y futuro, a la vez que conjugan lo individual con lo universal y los elementos que componen una estructura, tanto social como psíquica.

\section{Conclusión: Mito y estructura psíquica. Los dioses, sus representantes y la castración}

Ahora bien, ¿cómo puede pensarse la estructura de los mitos en el sujeto? Para explicar esto revisemos un poco el concepto de estructura en Lacan. Para ello nos interesa recuperar lo expuesto por Lacan en su escrito Subversión del sujeto y lo que María del Carmen Marlats expone sobre el tema de la noción de estructura lacaniana en una de sus clases teóricas. Lacan define la estructura primero como un todo completo, asegurando que existe una falta, pero que esta se encuentra en lo biológico. Luego la definirá como un conjunto de elementos covariantes, pero postulando que la falta se encuentra en la estructura misma puesto que su acercamiento a la matemática le permitió pensar la existencia de lugares vacíos en la estructura. Pero finalmente dirá que en la estructura en sí misma no falta nada, en tanto que el falo es el significante de la falta (Marlats, 2001). Agregado a lo dicho por Marlats, diríamos que porque hay falta es necesario el falo como significante de esa falta. 
Nos parece fundamental relacionar los lugares que ocupa el Otro en el grafo del deseo -en particular el hecho de que aparece en un momento sin barrar y en otro barrado, castrado ${ }^{4}$ - con el concepto de estructura completa; pero en la cual existe un significante que apunta a la falta y la función que cumplen los mitos en esta estructura. Nuestra hipótesis es que los mitos cumplen la función de velar la castración en el Otro en tanto que representante de la cultura para preservar imaginariamente en la misma operación la estructura como una totalidad completa. Es decir, el mito vela la castración -esto es, la falta, el che vuoi? que pone en evidencia que el Otro no tiene todas las respuestas para el sujeto- en quienes ocupan la posición del Otro para el sujeto (padres, maestros, otros significativos) para preservar ${ }^{5}$ imaginariamente el tesoro de los significantes que es el Otro de la estructura (la estructura en sí).

Ahora bien, hemos utilizado desde el principio la palabra "velar" para hacer referencia a la operación que el mito realiza para completar imaginariamente la falta real en el Otro. Esto se debe a que el mito no puede explicar ni dar cuenta acabada de la castración del Otro, en tanto que la castración es indecible. En este sentido, el mito da una forma discursiva a lo que no puede decirse, expresa de modo imaginario algo que solo puede decirse a través de una ficción. Sin embargo, esto no le quita legitimidad a la operación mítica ni al Otro, puesto que, tal como dijo Lacan, la verdad tiene una estructura de ficción, la verdad, de hecho, y en contraposición al saber, solo puede decirse a través de ficciones. En el mito se trata, entonces, de una explicación; pero tomando la palabra explicación muy entrecomillada, pues se refiere a una explicación que cumple su función explicativa únicamente en el plano imaginario.

Podemos avanzar, entonces, en esta última hipótesis: en el relato mítico, a través de la referencia a los dioses, el ser humano acepta la castración de los representantes del Otro que, él, incompleto, representa; no obstante, a una totalidad en sí misma completa (aunque solo en el nivel imaginario). Es decir, no existe falta en el Otro en tanto tesoro de los significantes, o sea, en la estructura en sí, y los dioses (o clásicos del arte y la ciencia, o líderes políticos consagrados) son garantes de esta completud imaginaria, pues en sus acciones se pueden encontrar todas las respuestas, aunque sus representantes sean sacerdotes, padres, amos, políticos de turno, etc. incapaces de encontrarlas o referirse a ellas. Por lo tanto, la castración, la falta, existe en el Otro como representante de la cultura. Es menester recalcar que la falta existe también en la cultura misma, puesto que no hay Otro completo ni consistente más que a nivel imaginario.

Es de suma importancia remarcar que esta es una hipótesis con la que cerramos este trabajo más que nada a título de provocación para futuras indagaciones, pues no se sostiene más

$4 \quad$ El Otro sin barrar en el grafo muestra un momento mítico. Se ubica en el piso inferior del grafo. El S(A) en el piso superior indica que siempre falta un significante; en el Otro hay una falta. Es decir, en el tesoro de los significantes, constituido por el Otro, siempre falta un significante. De eso da cuenta el complejo de castración para el sujeto. 
que por nuestra propia especulación. Mas resulta interesante como punto de relación entre los conceptos que hemos venido trabajando de la mano de Lévi-Strauss con el concepto de estructura de Lacan.

\section{Referencias}

Diario El País Digital (2013). Editorial: Stalin en el recuerdo. Disponible en http://historico.elpais.com. uy/130312/predit-701863/editorial/stalin-en-el-recuerdo/. Montevideo, Uruguay.

Lacan, J. (2012 [1966]). Subversión del sujeto. En Escritos 2, Buenos Aires: Siglo XXI.

Lacan, J. (2012)....O peor. El seminario libro 19. Buenos Aires: Paidos.

Lévi-Strauss, C. (2011). Antropología estructural. Barcelona: Paidós.

Lévi-Strauss, C. (1974). Estructuras elementales de parentesco. Barcelona: Paidós

Marlats, M. del C. (2001). Concepto de estructura. Psicoanálisis: Escuela Francesa. Facultad de Psicología. Universidad de Buenos Aires. Disponible en www.psi.uba.ar/.../psicologia/.../ francesa $1 / . . . / T e o \% 20$ Estructura\%202006.doc. 